\title{
Potential surge in post-COVID child tooth extractions
}

Latest figures showing nearly 45,000 hospital operations to remove decayed teeth in children and teenagers - equating to 177 a day - have led councils to warn of a potential post-coronavirus surge of dental treatments following the lifting of lockdown.

The Local Government Association (LGA), which represents councils, says the stark numbers highlight the dangers of too much sugary food and drink in children's diets, as well as poor oral hygiene, which is likely to have worsened during the last few months, while children and teenagers have been confined to the indoors.

There were 44,685 extractions of multiple teeth in under-18s in England in 2018/19 at a cost of $£ 41.5$ million, according to latest NHS spending data. This is equal to 177 per working day, an increase of $17 \%$ compared to the 38,208 extractions in $2012 / 13$, which cost $£ 27.4$ million.

Early years settings including nurseries

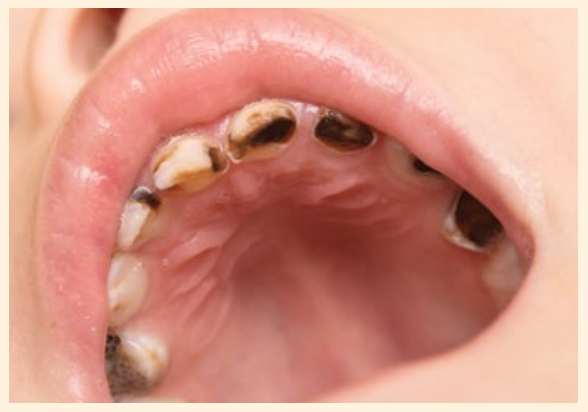

and schools closures have also led to the loss of supervised brushing time and fewer opportunities to educate young children and parents about good oral health. Councils, schools and other educational settings are keen to restart supervised brushing schemes and scale up their oral health work, to avoid an increase in tooth decay and extractions, but need the additional funding and capacity to help do so.

The British Society of Paediatric Dentistry (BSPD) said that it agrees with the LGA that there should be a resumption in toothbrushing schemes in early years settings as soon as practical. It would also like to see children suffering from dental decay treated in primary care where possible, to reduce the need for onward referral into hospital. The BSPD has been producing resources to support GDPs to provide silver diamine fluoride, a technique which arrests the progress of decay and may avoid the need for a general anaesthetic (https://www.bspd. co.uk/Professionals/Resources).

The LGA is calling for councils prevention efforts to be fully funded to help keep children's teeth healthy, including reversing a reduction of more than $£ 700$ million in the public health grant to councils between 2015/16 and 2019/20. The public health grant to councils should also be increased to at least $£ 3.9$ billion a year by $2024 / 25$, so it matches the growth in overall NHS funding, as part of the NHS Long-Term Plan.

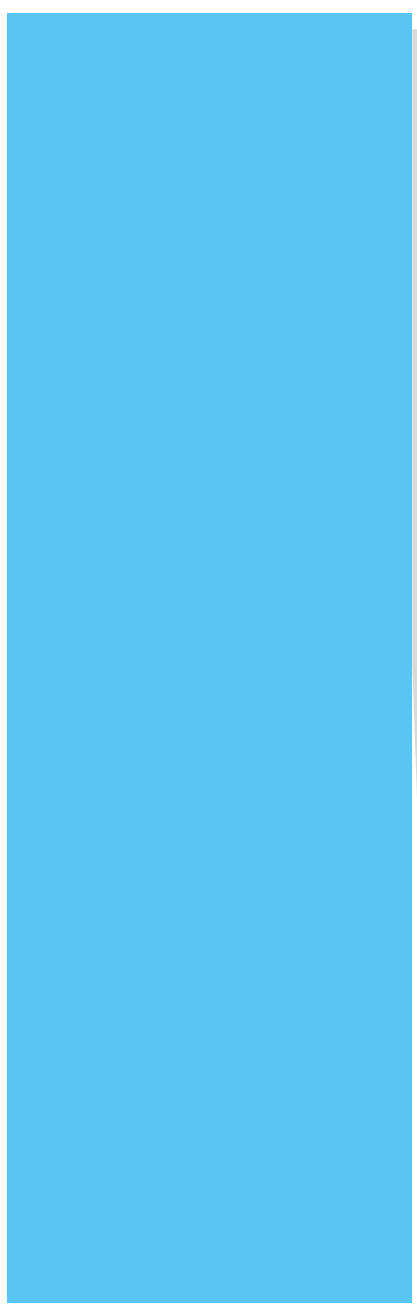

